\title{
Modification of Cytochrome $c$ by 4-Hydroxy- 2-Nonenal: Evidence for Histidine, Lysine, and Arginine-Aldehyde Adducts
}

\author{
Amanda L. Isom* and Stephen Barnes*,+ \\ Departments of Pharmacology and Toxicology, University of Alabama at Birmingham, Birmingham, Alabama, \\ USA
}

\author{
Landon Wilson, Marion Kirk, and Lori Coward \\ Comprehensive Cancer Center Mass Spectrometry Shared Facility, University of Birmingham, Birmingham, \\ Alabama, USA
}

\author{
Victor Darley-Usmar \\ Department of Pathology, University of Alabama at Birmingham, Birmingham, Alabama, USA
}

\begin{abstract}
4-Hydroxy-2-nonenal (4HNE), a major secondary product of lipid peroxidation, has been associated with a number of disease states involving oxidative stress. Despite the recognized importance of post-translational modification of proteins by products such as $4 \mathrm{HNE}$, little is known of the modification of cytochrome $c$ by this reagent and its analysis by mass spectrometry. The purpose of this study was to investigate the chemical interaction of $4 \mathrm{HNE}$ and cytochrome $c$, a protein essential to cellular respiration, under in vitro conditions. Isoelectric focusing of native and $4 \mathrm{HNE}$-modified cytochrome $c$ using immobilized $\mathrm{pH}$ gradient (IpG) strips showed a decrease in the pI of the 4HNE-modified protein suggesting modification of charged amino acids. Reaction of $4 \mathrm{HNE}$ with cytochrome $c$ resulted in increases in molecular weight consistent with the addition of four $4 \mathrm{HNE}$ residues as determined by matrix-assisted laser desorption time-of-flight mass spectrometry (MALDI-TOF MS). Samples of both native and 4HNE-modified cytochrome $c$ were enzymatically digested and subjected to peptide mass fingerprinting using MALDI-TOF MS. Analysis of these samples using LC-electrospray ionization tandem mass spectrometry (LC-ESI-MS/MS) provided sequence information that was used to determine specific residues to which the aldehyde adducted. Taken together, the data indicated that H33, K87, and R38 were modified by $4 \mathrm{HNE}$. Mapping these results onto the X-ray crystal structure of native cytochrome $c$ suggest that $4 \mathrm{HNE}$ adduction to cytochrome $c$ could have significant effects on tertiary structure, electron transport, and ultimately, mitochondrial dysfunction. (J Am Soc Mass Spectrom 2004, 15, 1136-1147) @ 2004 American Society for Mass Spectrometry
\end{abstract}

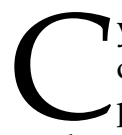
ytochrome $c$ is a $12 \mathrm{kDa}$ protein essential to cellular respiration in mitochondria that transports electrons between ubiquinol cytochrome $c$ oxidoreductase (Complex III) and cytochrome $c$ oxidase (Complex IV) [1]. Highly conserved among species, cytochrome $c$ contains a covalently bound heme group and nineteen lysine residues that contribute to the relatively high isoelectric point (pI) of 9.6 [2]. It is associated with the inner mitochondrial membrane

Published online July 2, 2004

Address reprint requests to Dr. S. Barnes, Department of Pharmacology and Toxicology, University of Alabama at Birmingham, 1918 University Blvd., McCallum Bldg. 452, Birmingham, AL 35294, USA E-mail: sbarnes@uab.edu *Also at the Botanicals Center for Age-Related Disease, Purdue UniversityUniversity of Alabama at Birmingham.

${ }^{+}$Also at the Comprehensive Cancer Center Mass Spectrometry Shared Facility, University of Alabama at Birmingham. through its interactions with cytochrome $c_{1}$ and subunit II of cytochrome $c$ oxidase and is found in relatively high concentration (approximately $400 \mu \mathrm{M}$ ) in mitochondria [3-9]. Cytochrome $c$ also plays an important role in cellular apoptosis contributing to the formation of the apoptosome once released into the cytosol and the initiation of caspase activation [10].

4 -Hydroxy-2-nonenal (4HNE) is a highly reactive $\alpha, \beta$ unsaturated aldehyde and a major secondary product of lipid peroxidation [11, 12]. Reports estimate normal rat liver $4 \mathrm{HNE}$ concentrations in the range of 0.4 to 2.8 $\mathrm{nmol} / \mathrm{g}$ wet weight [13]. Studies concerning the covalent adduction of $4 \mathrm{HNE}$ to cellular target proteins have demonstrated that $4 \mathrm{HNE}$ can interact with and in some cases inhibit a variety of enzymes, including the adenine nucleotide translocator and Complex III of the mitochondrial electron transport chain [14-16]. Immu- 


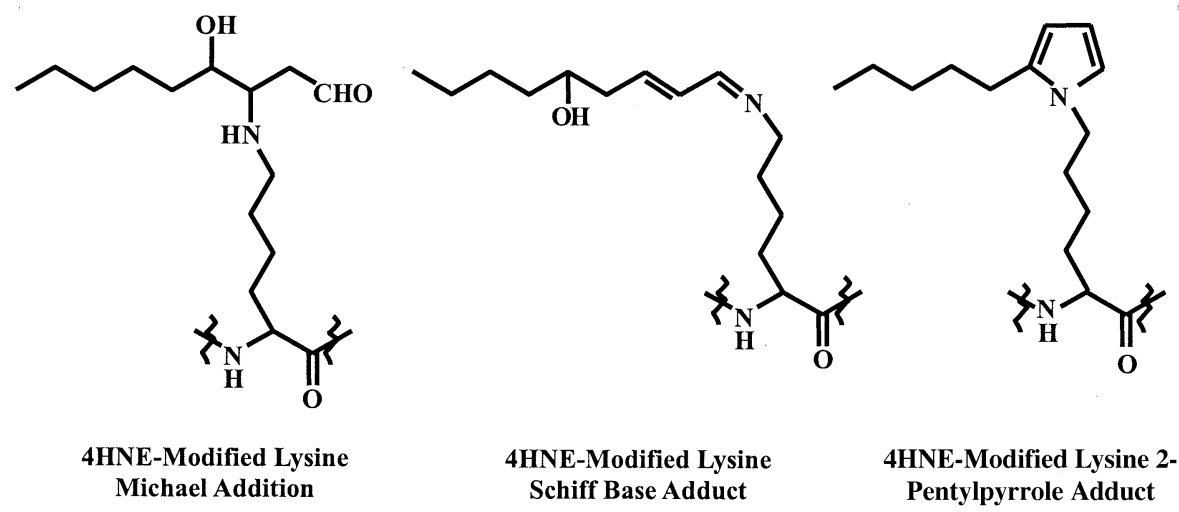

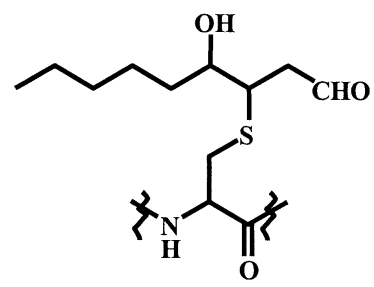

4HNE-Modified Cysteine Michael Addition

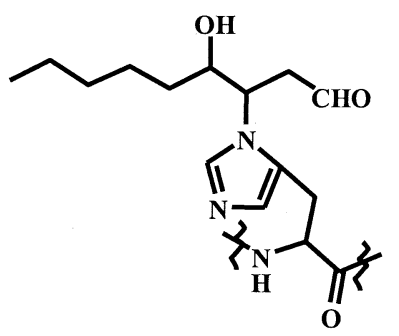

4HNE-Modified Histidine Michael Addition

Figure 1. Structures of amino acids modified by 4-hydroxy-2-nonenal.

nohistochemical detection using anti-HNE antibodies has shown that $4 \mathrm{HNE}$-protein modifications exist in disease states including atherosclerosis, bacterial meningitis, olivopontocerebellar atrophy, and chronic obstructive pulmonary disorder [17-20]. More recently, it has been demonstrated that $4 \mathrm{HNE}$ reacts with epithelial fatty acid binding protein in vivo [21].

Lipid peroxidation and mitochondrial dysfunction in general have been associated with a number of chronic oxidative disease states including neurodegenerative diseases, prion diseases, ethanol-associated liver injury, and injury from ischemia/reperfusion [24-30]. As it is a significant component of the mitochondrial inner membrane, cytochrome $c$ represents a potential target of adduction by secondary products of lipid peroxidation, an event known to occur in the highly oxidizing environment of the mitochondria due to the presence of significant amounts of reactive oxygen species that can initiate degradation of lipid molecules [31]. The modification of cytochrome $c$ by electrophilic lipid degradation products such as $4 \mathrm{HNE}$ could result in altered tertiary structure and an initiation of events leading to the inhibition of cellular respiration and mitochondrial function, both contributing further to oxidative stress.

Amino acids modified by $4 \mathrm{HNE}$ have nucleophilic groups (histidine, lysine, and cysteines) which form Michael adducts (Figure 1). 4HNE-modified lysines have also been characterized in both Schiff base and 2-pentylpyrrole forms [22, 23, 33]. A Michael addition to lysine or histidine residue results in a mass shift of 156 .
In Schiff base condensation reactions with protein lysine residues, there is a concomitant loss of water resulting in a mass addition of 138. Other adducts include the 4HNE-lysine 2-pentylpyrrole adduct formed from the double dehydration of a Michael adduct which results in a mass increase of 120 .

Although cytochrome $c$ has not been identified to date as a target for the direct modification of $4 \mathrm{HNE}$ in mitochondria, it has several advantages for these studies including a detailed crystal structure and several nucleophilic centers that have the potential to react with this lipid oxidation product. In the present study, $4 \mathrm{HNE}$ modification of cytochrome $c$ has been investigated by characterization of molecular weight increases using matrix-assisted laser desorption ionization time of flight mass spectrometry (MALDI-TOF MS). Identification of additional sites found on proteolytic peptides using MALDI-TOF and LC-ESI tandem mass spectrometry was also performed along with isoelectric focusing used to separate different $\mathrm{pI}$ states of modified protein.

\section{Materials and Methods}

\section{Materials}

Horse heart cytochrome $c$ was obtained from Sigma Chemical Company, St. Louis, MO. Dibasic potassium phosphate and screw glass vials were obtained from Fisher, Norcross, GA. Spin-X centrifuge tubes with 0.45 $\mu \mathrm{m}$ cellulose acetate filters were obtained from Costar, 
Corning, NY. G-25 Sephadex beads and Immobiline DryStrip pH 6-11, $11 \mathrm{~cm}$ IpG strips were obtained from Amersham-Biosciences, Piscataway, NJ. Porozyme bulk immobilized trypsin was obtained from Applied Biosystems Inc., Framingham, MA. Sequencing-grade chymotrypsin was obtained from Roche Diagnostics Corp., Indianapolis, IN. $\alpha$-Cyano-4-hydroxycinnamic acid (CHCA) and 3,5-dimethoxy-4-hydroxy-cinnamic acid (sinapinic acid) were obtained from Aldrich, Milwaukee, WI. 4HNE was obtained from CalBiochem, La Jolla, CA. Tri-buytl phosphine was obtained from Bio-Rad Laboratories Inc, Hercules, CA. All other reagents were of reagent grade quality unless specified.

\section{Modification of Cytochrome c by $4 \mathrm{HNE}$}

Cytochrome $c$ was modified by $4 \mathrm{HNE}$ using a procedure adapted from the method published previously by Bolgar and Gaskell [23]. Briefly, cytochrome c (2 mg/ $\mathrm{ml}$ ) was incubated with $50 \mathrm{mM} \mathrm{K}_{2} \mathrm{HPO}_{4} \mathrm{pH} 7.4$ and 4 $\mathrm{mM} 4 \mathrm{HNE}$ at $37^{\circ} \mathrm{C}$ for $2 \mathrm{~h}$. The reaction was terminated by the addition of $25 \mu \mathrm{L}$ of $1 \%$ ( $\mathrm{vol} / \mathrm{vol}$ ) formic acid. The mixture was passed through a Sephadex G-25 column to remove excess buffer and unreacted $4 \mathrm{HNE}$. Concentration-dependent studies were conducted similarly using cytochrome $c(100 \mu \mathrm{M})$ and concentrations of $4 \mathrm{HNE}$ ranging from $50 \mu \mathrm{M}$ to $1.6 \mathrm{mM}$. The cytochrome $c$ used in these experiments is in the ferric oxidation state as determined by UV/VIS spectrophotometry.

\section{Isoelectric Focusing Studies}

Isoelectric focusing of native and $4 \mathrm{HNE}$-modified cytochrome $c$ was performed on a Multiphor II (AmershamPharmacia Biosciences). Protein samples were diluted to the appropriate volume with a rehydration buffer consisting of $7 \mathrm{M}$ urea, $2 \mathrm{M}$ thiourea, 4\% 3-[(3-cholamidopropyl) dimethylammonio]-1-propane-sulfonate (CHAPS), 2\% ampholytes, and $5 \mathrm{mM}$ tri-butyl phosphine (TBP). Protein $(50 \mu \mathrm{g})$ of each sample was applied to immobilized, $11 \mathrm{~cm}$ linear $\mathrm{pH}$ 6-11 strips and allowed to rehydrate passively overnight. Focusing occurred in three steps. Step one consisted of a conditioning step of $300 \mathrm{~V}$ for one min. Step two was a gradient up to $3500 \mathrm{~V}$ over 90 min. Step three involved focusing the strips at a constant voltage of $3500 \mathrm{~V}$ for $5 \mathrm{~h}$. The total volt-hours approximated 17,500 . Strips were subsequently analyzed using a GS-800 scanner (Bio-Rad Laboratories, Hercules, CA) and PDQuest analysis software (Bio-Rad Laboratories).

\section{Protein Analysis by Mass Spectrometry}

Undigested native and 4HNE-modified cytochrome $c$ were analyzed by MALDI-TOF MS to detect changes in total protein mass. Briefly, samples were mixed 1:10 ( $\mathrm{vol} / \mathrm{vol})$ with a saturated solution of sinapinic acid in $50 \%$ aqueous acetonitrile/ $0.1 \%$ aqueous trifluoroacetic acid (1:1, vol/vol) and $1 \mu \mathrm{L}$ spotted onto the stainless steel MALDI target plate and allowed to dry before analysis by MALDI-TOF MS. Protein molecular ions were analyzed in linear, positive ion mode using a Voyager Elite mass spectrometer (Applied Biosystems). Using an acceleration voltage of $25 \mathrm{kV}$ and a laser intensity of $2500 \mathrm{~V}$, each spot was analyzed a minimum of three times, accumulating spectra composed of approximately 200 laser shots in total. The resulting spectra were analyzed by DataExplorer (Applied Biosystems, Inc). The instrument was calibrated using an external apomyoglobin standard and the resulting spectra were Gaussian-smoothed and baseline-corrected.

Tryptic and chymotryptic peptide maps were generated for the native and 4HNE-modified cytochrome $c$. These digests were used to identify the peptides to which an addition of $4 \mathrm{HNE}$ had occurred by comparison of $m / z$ shifts. Immobilized trypsin (Applied Biosystems, Inc.) ( $3 \mu \mathrm{L})$ was loaded into a gel loading tip, washed with $50 \%$ aqueous acetonitrile containing 25 $\mathrm{mM}$ ammonium bicarbonate, and subsequently charged with $25 \mathrm{mM}$ ammonium bicarbonate. Five $\mu \mathrm{L}$ of sample was loaded onto the column and allowed to digest for $10 \mathrm{~min}$. Peptides were eluted with 3 washes of $50 \%$ aqueous acetonitrile containing $25 \mathrm{mM}$ ammonium bicarbonate and diluted 1:10 (vol/vol) with a saturated solution of CHCA in $50 \%$ aqueous acetonitrile/0.1\% trifluoroacetic acid. Samples were also incubated with chymotrypsin diluted in $25 \mathrm{mM}$ ammonium bicarbonate (1:10 ratio of protein to enzyme). Digestion proceeded overnight at room temperature. After digestion, one $\mu \mathrm{L}$ of the digest was diluted 1:10 (vol/vol) with a saturated solution of CHCA in $50 \%$ aqueous acetonitrile $/ 0.1 \%$ aqueous trifluoroacetic acid (1:1, vol/vol), and one $\mu \mathrm{L}$ spotted onto the MALDI target plate and allowed to dry before analysis by MALDI-TOF MS.

Following proteolysis, peptide molecular ions were analyzed in the reflector mode using a Voyager Elite mass spectrometer with an acceleration voltage of 20 $\mathrm{kV}$. Each sample was analyzed a minimum of three times, accumulating spectra composed of approximately 200 laser shots total. The resulting spectra were analyzed by DataExplorer (Applied Biosystems). The instrument was calibrated internally using a trypsin or chymotrypsin autolysis peak and the resulting spectra were baseline-corrected and noise-filtered. For peptide mass fingerprinting, peptide mass maps were compared between native and $4 \mathrm{HNE}$-modified cytochrome $c$ samples in order to identify $m / z$ shifts of 120,138 , or 156 corresponding to the presence of $4 \mathrm{HNE}$ pyrrole, Schiff base, or Michael adducts.

LC-ESI-Tandem mass spectrometry (LC-ESI-MS/ MS) was performed on native and 4HNE-modified peptides using a Waters Corp. (Milford, MA) quadrupole-orthogonal time of flight (QTOF) II MS with automatic switching between MS and MS/MS modes. Five $\mu \mathrm{L}$ of the peptide solutions were separated by HPLC on a $15 \mathrm{~cm} \times 75 \mu \mathrm{m}$ i.d. reverse-phase $C_{18}$ column using a 20 min linear gradient of 5 to $100 \%$ acetonitrile in $0.1 \%$ 


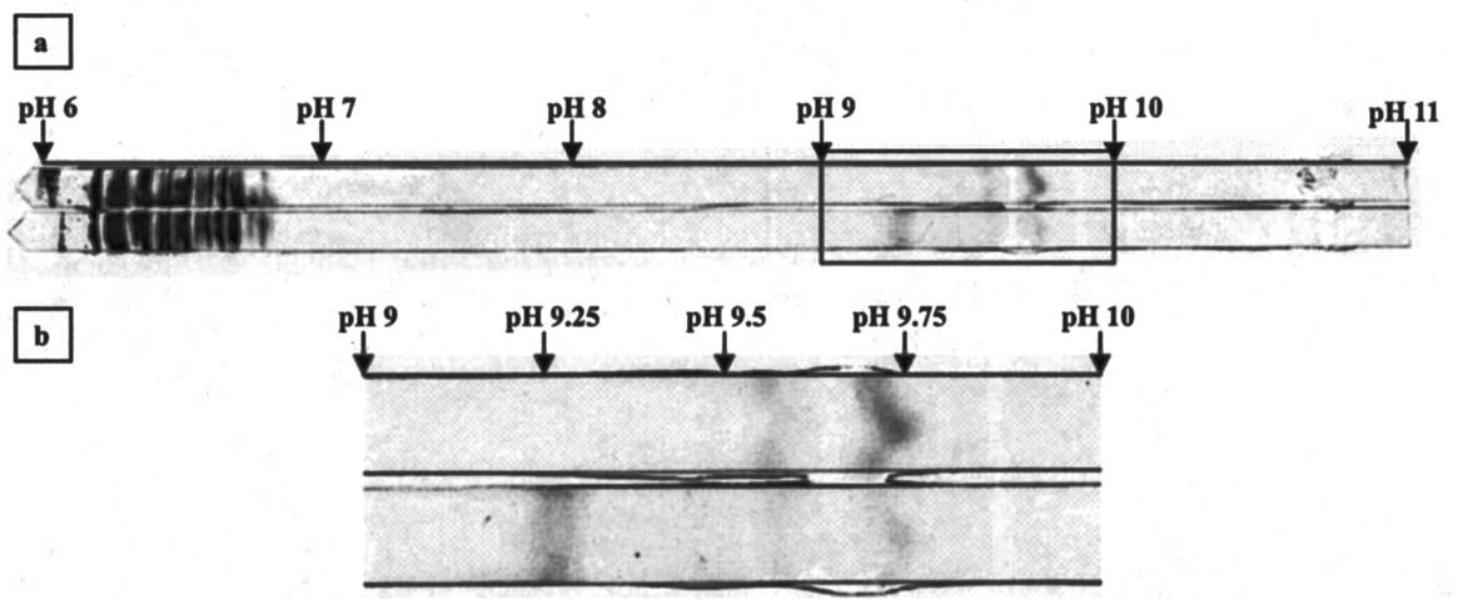

Figure 2. Isoelectric focusing of native and 4 HNE-modified cytochrome $c$. Simplified scales are included to give an approximate $\mathrm{pH}$ range. (a) Entire pI range 6-11 IpG strips used to focus samples. The top strip shows separation of species present in native cytochrome $c$. The bottom strip shows separation of species present in $4 \mathrm{HNE}-$ modified cytochrome $c$. (b) Expanded view of the $\mathrm{pH}$ range 9-10 from (a).

formic acid and at a flow rate of $200 \mathrm{~nL} \mathrm{~min}^{-1}$. Daughter ion spectra were processed using MaxENT (Waters Corp.) software. Selected ion extraction of $\mathrm{m} / \mathrm{z} 139$ representing a protonated, dehydrated $4 \mathrm{HNE}$ moiety, was used to identify 4 HNE-modified peptides.

\section{Results and Discussion}

\section{Isoelectric Focusing Studies}

Figure 2 shows the results of isoelectric focusing of native and 4HNE-modified cytochrome $c$ using IpG strips. Linear IpG strips were used to separate the cytochrome $c$ variants in both the native and 4HNEmodified protein samples. As such, a simplified scale can be drawn representing equal segments of the strip and qualitative measurements regarding the pI shifts can be made. In the inset of Figure 2a, the top strip shows focusing of native cytochrome $c$ and the bottom strip represents the different species present in the 4 HNE-modified protein. The majority of the native protein migrates to an approximate $\mathrm{pI}$ of 9.70 with a minor band at 9.56. In contrast, the 4 HNE-modified cytochrome $c$ has an additional band that moved toward the acidic end of the IpG strip to an apparent pI of 9.25. The pI 9-10 range of the IpG strips is shown enlarged in Figure 2b. Qualitatively from the simplified scale, a decrease in pI of some variants of the 4HNEmodified sample can be seen. The decreased $\mathrm{pI}$ of the additional band found in the $4 \mathrm{HNE}$-modified protein suggests aldehyde modification of positively charged lysines and arginines. As shown in Figure $2 \mathrm{a}$ and $\mathrm{b}$, it is apparent that complete aldehyde modification of cytochrome $c$ did not occur as faint bands corresponding to native cytochrome $c$ still exist in the 4HNEmodified sample. It is also probable that while appearing as one band, the new band is heterogenous and represents a number of products of the aldehydemodified protein. Taken together, these data suggest $4 \mathrm{HNE}$ adduction to positively charged amino acids resulting in an overall decreased isoelectric point of cytochrome $c$.

\section{HNE Modification of Cytochrome c-Intact Protein Mass Change Determination}

From MALDI-TOF analysis, 4HNE-adducted cytochrome $c$ is composed of four different modified protein states (Figure $3 b$ ). For purposes of these studies, the average molecular weight of unmodified cytochrome $c$ is $12361.96 \mathrm{Da}$. Starting from native cytochrome $c$ shown in Figure 3a at $\mathrm{m} / \mathrm{z}$ 12365, $4 \mathrm{HNE}$ forms as many as four covalent Michael additions as seen in Figure $3 \mathrm{~b}$ $(\mathrm{m} / \mathrm{z} 12522,12680,12838,12994)$. A putative matrix adduct to the native protein is also seen in Figure $3 \mathrm{a}$ at $\mathrm{m} / \mathrm{z} 12575$.

Analysis of the effect on adduct formation of increasing amounts of HNE was carried out using MALDITOF MS. The goal was to assess whether there was preferential adduct formation at specific sites on the protein since in vivo the $4 \mathrm{HNE}$ concentration (and hence the molar ratio) could be limiting with respect to cytochrome $c$. Unreacted cytochrome $c(100 \mu \mathrm{M})$ shown in Figure $4 \mathrm{a}$ at $\mathrm{m} / \mathrm{z} 12360$ was modified by increasing concentrations of $4 \mathrm{HNE}$ from $50 \mu \mathrm{M}$ (Figure $4 \mathrm{~b}$ ) to 1.6 $\mathrm{mM}$ (Figure 4g). Each sample was spotted on the MALDI target five times and the resulting spectra analyzed for the presence of aldehyde adducts. Average molecular weights are presented in the figure. Under the conditions of this experiment, several cytochrome $c$ modified species were observed including aldehyde additions to the putative sinapinic acid-cytochrome $c$ adduct. Figure 4a shows the spectrum resulting from 


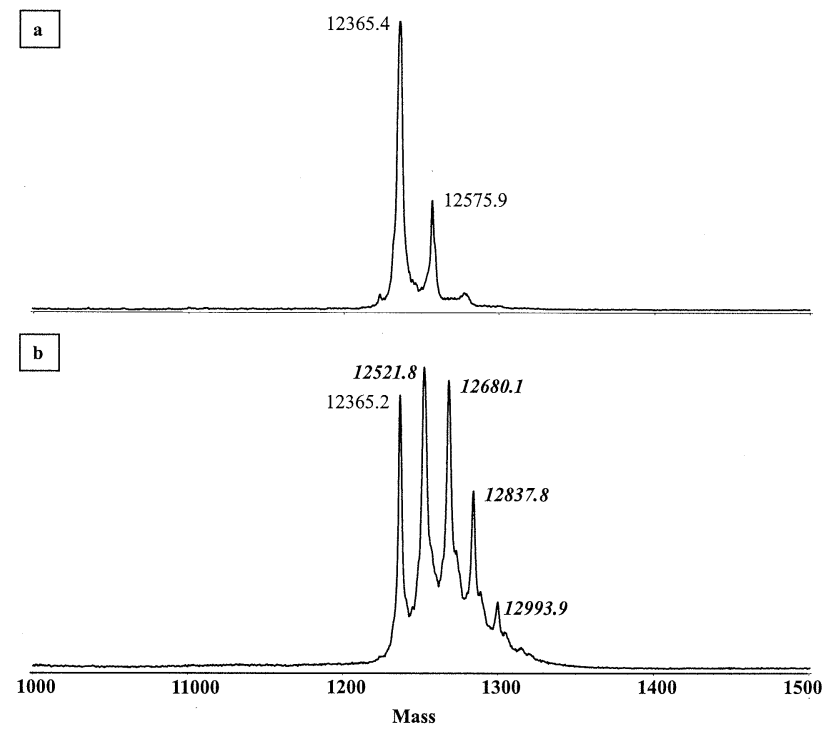

Figure 3. Mass spectra showing shifts in cytochrome $c$ molecular weight due to aldehyde modification. Cytochrome $c(2 \mathrm{mg} / \mathrm{mL})$ was incubated with $10 \mathrm{mM} 4 \mathrm{HNE}$ to create the aldehyde-modified protein. (a) MALDI-TOF mass spectrum of native cytochrome $c$. (b) MALDI-TOF mass spectrum of $4 \mathrm{HNE}$-adducted cytochrome $c$. Italicized, bolded numbers represent aldehyde modifications.

the analysis of native cytochrome $c$. A putative matrix adduct is seen at $m / z$ 12569.7. At a molar ratio of $0.5: 1$ aldehyde to protein, a potential Michael addition is apparent at $12517 \mathrm{Da}$ (Figure $4 \mathrm{~b}$ ). The intensity of the ion at $m / z 12517$ increases as the molar ratio of aldehyde to protein is increased to 1:1 (Figure 4c). Two Michael additions $(\mathrm{m} / \mathrm{z} 12517$ and 12672$)$ are present as the molar ratio increased to 2:1 along with the first $156 \mathrm{Da}$ addition to the putative matrix adduct at $\mathrm{m} / \mathrm{z} 12724$ (Figure $4 \mathrm{~d}$ ). At a molar ratio of 4:1 aldehyde to protein, species containing triply-modified cytochrome $c$ are apparent at $m / z$ 12829, representing three possible Michael additions to the native protein. At an 8:1 molar ratio of aldehyde to protein shown in Figure $4 \mathrm{f}$, an additional ion at $12880 \mathrm{Da}$ appears which represents 2 Michael additions to the cytochrome $c$ matrix adduct. At the highest aldehyde to protein ratio of 16:1, the first quadruply-modified cytochrome $c$ species are present at $12981 \mathrm{Da}$. From this MALDI analysis at the highest aldehyde concentrations, as many as four $4 \mathrm{HNE}$ molecules can form adducts with cytochrome $c$.

Diagrams describing $4 \mathrm{HNE}$ adducts on cytochrome $c$ during increasing concentrations of aldehyde as determined by matrix-assisted laser desorption time of flight mass spectrometry (MALDI-TOF-MS) analysis are presented in Figure 5. The chart shown in Figure 5a outlines $4 \mathrm{HNE}$-cytochrome $c$ adducts formed and the specific concentrations at which they are detected.

Figure $5 b$ shows the percentage of total ion area for each of the ions present in Figure 5a normalized to the most abundant ion in each spectrum. Total ion area was determined by combining the areas under the curve for each spectrum. The average area and standard devia-

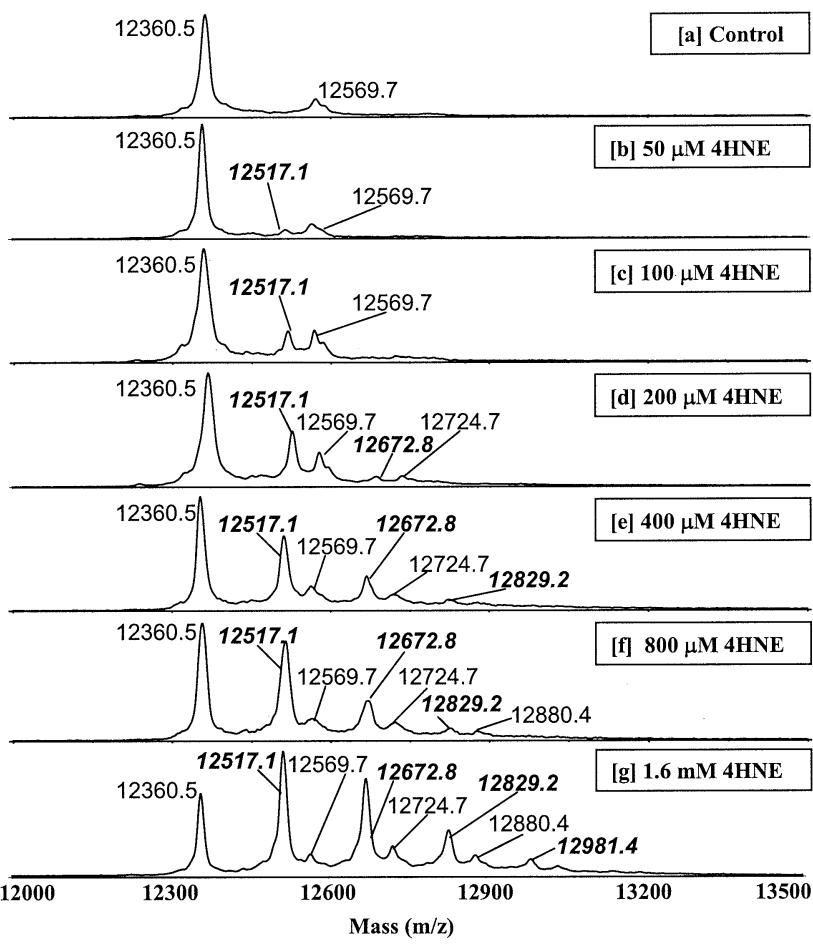

Figure 4. MALDI-TOF mass spectra of $100 \mu \mathrm{M}$ cytochrome $c$ modified by increasing concentrations of $4 \mathrm{HNE}$. Ion $\mathrm{m} / \mathrm{z}$ values representing aldehyde modifications are bolded in italics. (a) Native cytochrome $c$, (b) $50 \mu \mathrm{M} 4 \mathrm{HNE}$, (c) $100 \mu \mathrm{M} 4 \mathrm{HNE}$, (d) 200 $\mu \mathrm{M} 4 \mathrm{HNE}$, (e) $400 \mu \mathrm{M} 4 \mathrm{HNE}$, (f) $800 \mu \mathrm{M} 4 \mathrm{HNE},($ g) $1.6 \mathrm{mM}$ $4 \mathrm{HNE}$.

tion $(n=5)$ of each peak is shown. As expected, the area of the unreacted cytochrome $c$ ion at $m / z 12360$ decreased as the ratio of $4 \mathrm{HNE}$ to cytochrome $c$ increased. In contrast, the areas corresponding to the aldehyde adduct ions $(m / z 12517,12672,12829,12981$ from unreacted cytochrome $c$ ion $m / z$ 12360) increased as a function of increasing aldehyde concentrations.

Literature suggests Schiff base additions are labile in acid environments [13]. Therefore, these adducts should not be abundantly present in ESI or MALDI analysis due to the presence of acids in solvents or matricies. Bolgar and Gaskell [23] report the apparent addition of $4 \mathrm{HNE}$ via Schiff base formation to apomyoglobin as an artifact of the electrospray process. More specifically, these authors report the dehydration of $4 \mathrm{HNE}$ occurring as a consequence of the desolvation conditions of the electrospray interface. To avoid the problems of acid lability and artificial adduction created by ESI, derivatization of Schiff base adducts by reduction with sodium borohydride is commonly employed to stabilize adducts and conclude definitive addition of $4 \mathrm{HNE}$ to protein via a Schiff base mechanism [22].

Since modification of charged amino acids of $4 \mathrm{HNE}-$ adducted cytochrome $c$ was demonstrated by the isoelectric focusing studies described within, modification of lysine residues potentially in both Michael addition 


\begin{tabular}{|c|c|c|}
\hline $\begin{array}{c}\text { a } \\
\frac{\text { Adduct }}{\underline{m / z}}\end{array}$ & $\frac{\text { Modification }}{\text { Description }}$ & 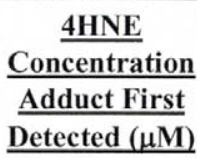 \\
\hline 12360.5 & Unmodified control ion & 0 \\
\hline 12517.1 & 1 Michael addition & 50 \\
\hline 12672.8 & 2 Michael additions & 200 \\
\hline 12829.2 & 3 Michael additions & 400 \\
\hline 12981.4 & 4 Michael additions & 1600 \\
\hline
\end{tabular}

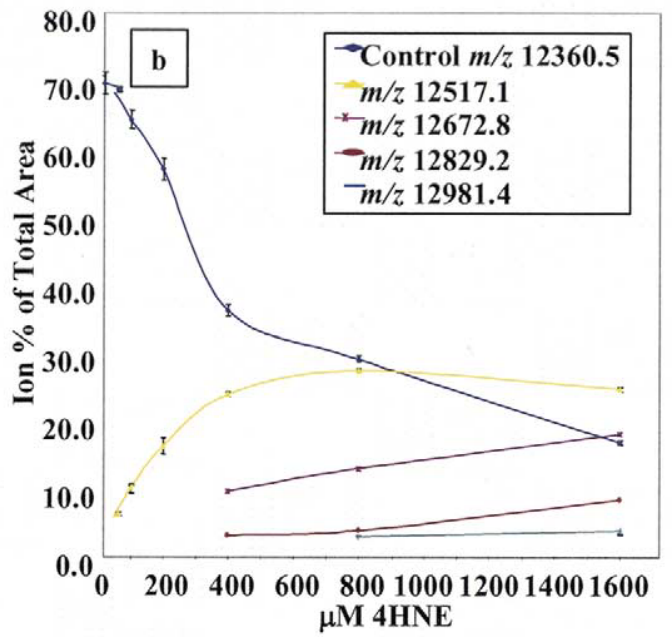

Figure 5. MALDI-TOF MS analysis of cytochrome $c$-4HNE adducts. (a) Table showing $\mathrm{m} / \mathrm{z}$ values from MALDI-TOF analysis of aldehyde adducted cytochrome $c$ species and the 4HNE concentration at which they first appeared. Aldehyde concentrations were the same as in Figure 4. Protein concentration was held constant at $100 \mu \mathrm{M}$. Each sample was spotted onto the MALDI target five times and the average $\mathrm{m} / \mathrm{z}$ was calculated. (b) Each ion present on the MALDI spectra was normalized to the most abundant ion and ranked using percent of total area under the curve. Ion percent of total area was graphed versus increasing $4 \mathrm{HNE}$ concentrations.

and Schiff base forms along with other charge residues including arginine was expected. Since reduction of samples was not performed and in order to avoid detection of artificial aldehyde adduction, the present study utilized MALDI-TOF MS rather than ESI to

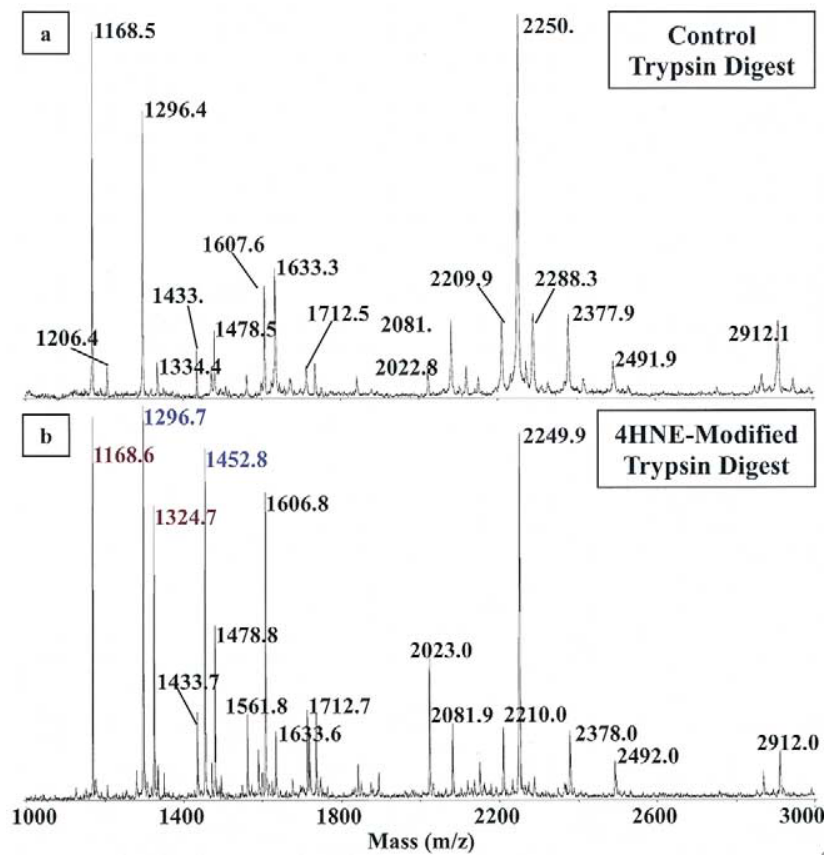

Figure 6. Peptide mass fingerprints of native and aldehydemodified cytochrome $c$ using MALDI-TOF-Trypsin digestion. Cytochrome $c(2 \mathrm{mg} / \mathrm{mL})$ was incubated with $4 \mathrm{mM} 4 \mathrm{HNE}$ to create the aldehyde-modified protein. (a) Tryptic digestion of native cytochrome $c$; (b) tryptic digestion of 4HNE-modified cytochrome $c$. Corresponding ion pairs representing unmodified and modified peptides are colored. analyze native and 4HNE-modified cytochrome $c$ samples of both intact and enzymatically digested protein. No Schiff base adducts were detected in the MALDI analysis shown in Figure 3b. It is possible that the mass

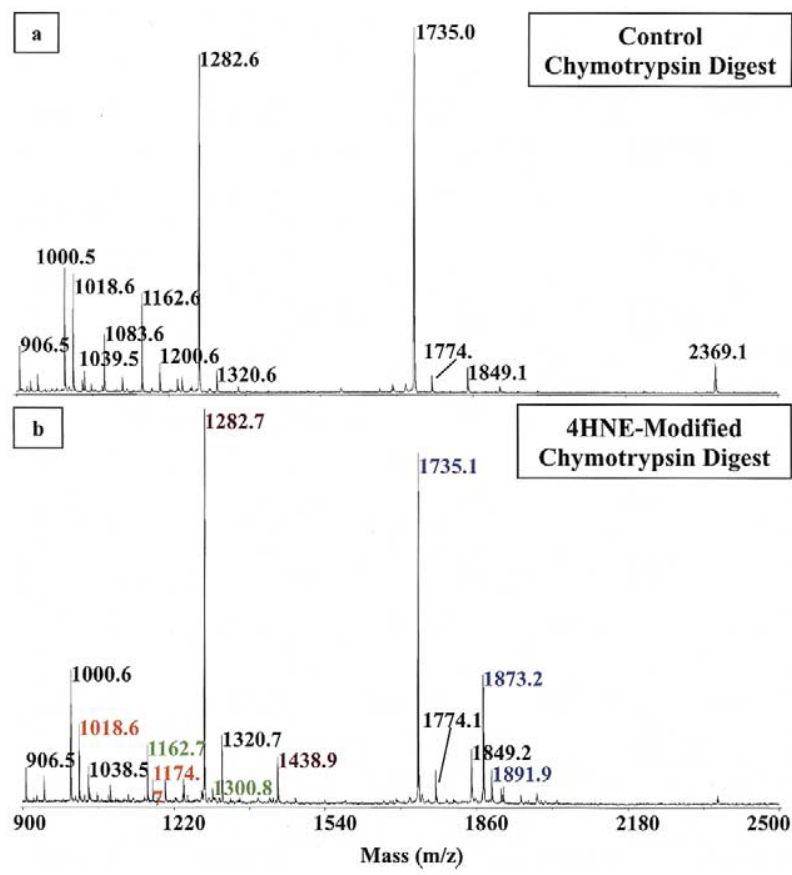

Figure 7. Peptide mass fingerprints of native and aldehydemodified cytochrome $c$ using MALDI-TOF-Chymotryptic digestion. Cytochrome $c(2 \mathrm{mg} / \mathrm{mL})$ was incubated with $4 \mathrm{mM} 4 \mathrm{HNE}$ to create the aldehyde-modified protein. (a) Chymotryptic digestion of native cytochrome $c$; (b) chymotryptic digestion of 4HNEmodified cytochrome $c$. Corresponding ion pairs representing unmodified and modified peptides are colored. 
Table 1. Native and 4HNE-modified cytochrome $c$ peptides observed by MALDI-TOF MS after enzymatic digestion

\begin{tabular}{lcccccc}
\hline Peptide sequence & Position & $\begin{array}{c}\text { Unmodified } \\
\text { peptide observed } \\
{[\mathrm{M}+\mathrm{H}]^{+}}\end{array}$ & $\begin{array}{c}\text { Unmodified } \\
\text { peptide calculated } \\
{[\mathrm{M}+\mathrm{H}]^{+}}\end{array}$ & $\begin{array}{c}\text { 4HNE-modified } \\
\text { peptide observed } \\
{[\mathrm{M}+\mathrm{H}]^{+}}\end{array}$ & $\begin{array}{c}\text { 4HNE-modifed } \\
\text { peptide calculated } \\
{[\mathrm{M}+\mathrm{H}]^{+}}\end{array}$ & $\begin{array}{c}\text { Type of } \\
\text { modification }\end{array}$ \\
\hline \hline GRKTGQAPGF & $37-46$ & 1018.7 & 1018.5 & 1174.7 & 1174.5 & Michael \\
Ac-GDVEKGKKIF & $1-7$ & 1162.6 & 1162.6 & 1300.8 & 1300.6 & Schiff Base \\
GRKTGQAPGFTY & $37-48$ & 1282.7 & 1282.6 & 1438.9 & 1438.6 & Michael \\
AGIKKKTEREDLIAY & $83-97$ & 1735.1 & 1734.9 & 1873.2 & 1872.9 & Schiff Base \\
AGIKKKTEREDLIAY & $83-97$ & 1735.1 & 1734.9 & 1891.9 & 1890.9 & Michael \\
TGPNLHGLFGR & $28-38$ & 1168.4 & 1168.6 & 1324.7 & 1324.6 & Michael \\
TGPNLHGLFGRK & $28-39$ & 1296.4 & 1296.7 & 1452.8 & 1452.7 & Michael \\
\hline
\end{tabular}

resolution in the MALDI analysis precluded detection of low abundance modifications and as such, only Michael adducts were observed upon analysis of intact protein. The acid lability of Schiff base moieties does not preclude detection by MALDI-TOF MS despite the presence of TFA in the matrix as putative aldehyde additions were detected upon chymotrypic peptide mass fingerprint analysis shown in Figure $7 \mathrm{~b}$.

\section{Peptide Mass Fingerprinting and Tandem MS} of Modified Peptides

Figure 6 shows the peptide mass fingerprint MALDITOF MS spectra generated for the native cytochrome $c$ and the $4 \mathrm{HNE}-$ modified protein for both trypsin digestion (Figure 6a and b, respectively) and chymotrypsin digestion (Figure $7 \mathrm{a}$ and $\mathrm{b}$, respectively). Upon compar-

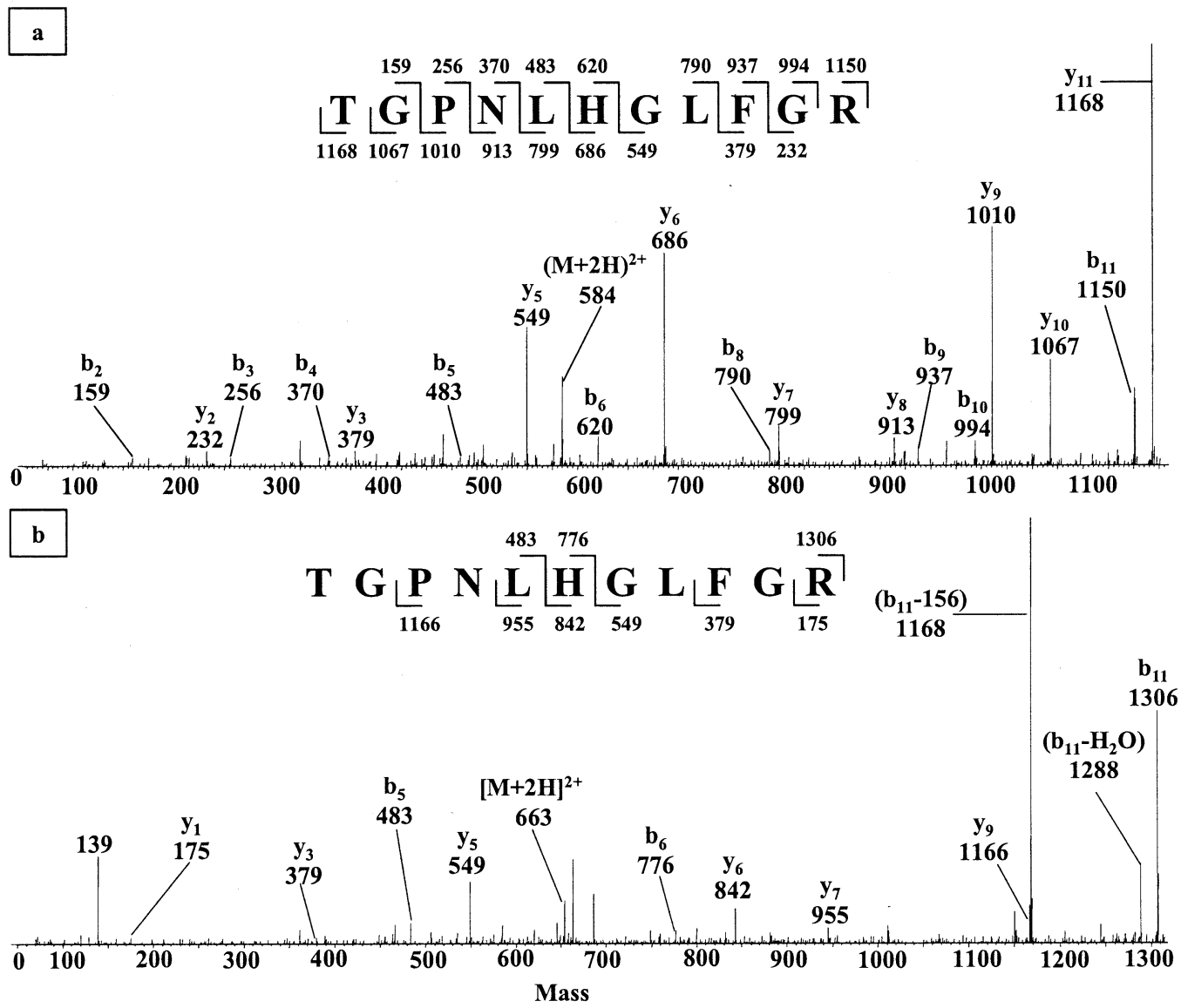

Figure 8. LC/MS/MS CID mass spectra of cytochrome $c$ using the QTOF. Cytochrome $c(2 \mathrm{mg} / \mathrm{mL})$ was incubated with $4 \mathrm{mM} 4 \mathrm{HNE}$ to create the aldehyde-modified protein. (a) Tryptically digested peptide TGPNLHGLFGR of native cytochrome $c$. $[\mathrm{M}+2 \mathrm{H}]^{+2} 584$ is shown; (b) tryptically digested peptide TGPNLHGLFGR of 4 HNE-modified cytochrome $c .[\mathrm{M}+2 \mathrm{H}]^{+2} 662$ is shown. Upon comparison of $\mathrm{b}$ and $\mathrm{y}$ ion fragmentation patterns, one $4 \mathrm{HNE}$ molecule modified His 33 forming a Michael addition. 


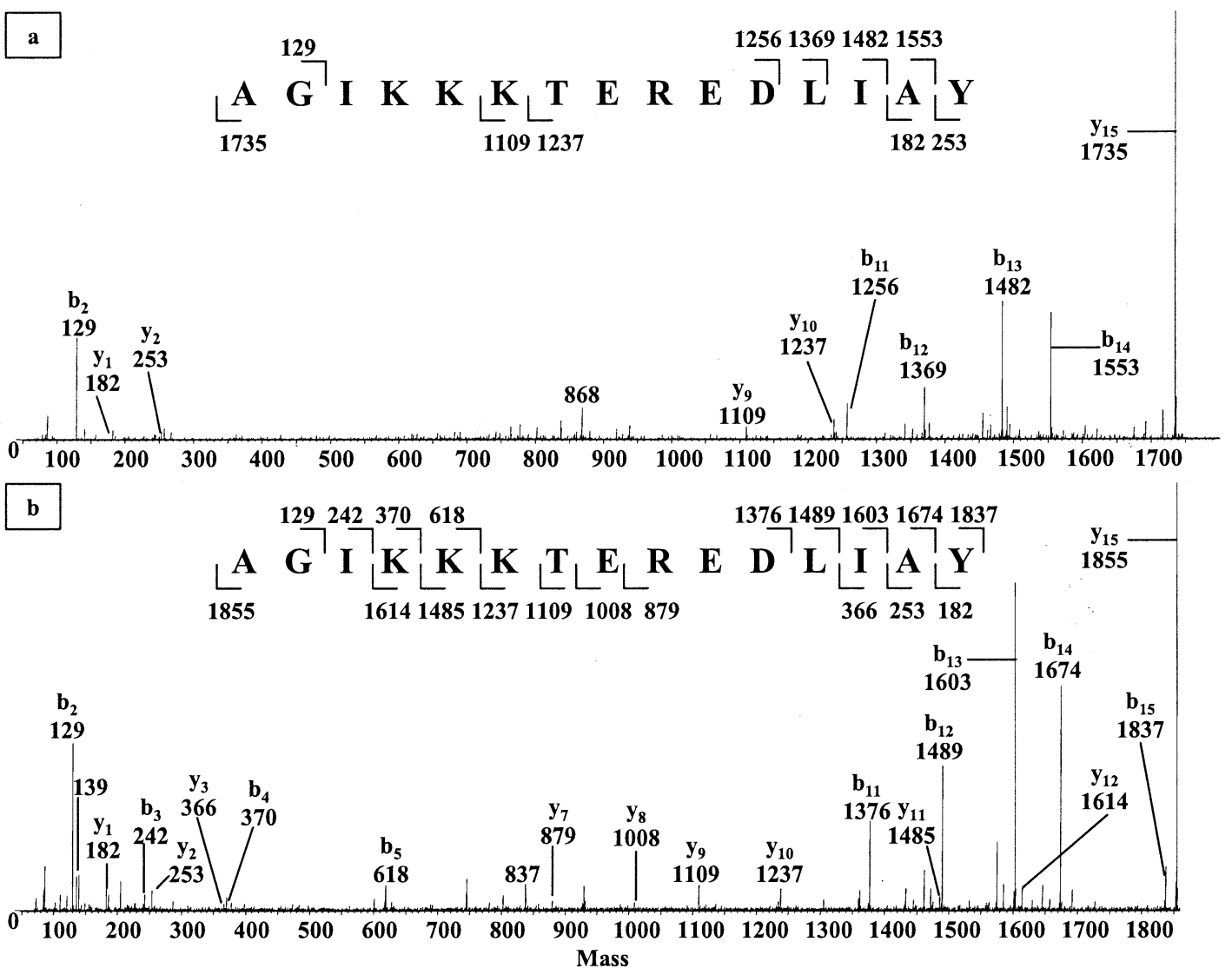

\begin{abstract}
Figure 9. LC/MS/MS CID mass spectra of cytochrome $c$ using the QTOF. Cytochrome $c(2 \mathrm{mg} / \mathrm{mL})$ was incubated with $4 \mathrm{mM} 4 \mathrm{HNE}$ to create the aldehyde-modified protein. (a) Chymotryptically digested peptide AGIKKKTEREDLIAY of native cytochrome $c$. $[\mathrm{M}+2 \mathrm{H}]^{+2} 868$ is shown; (b) chymotryptically digested peptide AGIKKKTEREDLIAY of native cytochrome $c$. $[\mathrm{M}+2 \mathrm{H}]^{+2} 928$ is shown. Upon comparison of $\mathrm{b}$ and $\mathrm{y}$ ion fragmentation patterns, Lys 87 is modified by a $4 \mathrm{HNE}$ moiety forming a 2-pentylpyrrole adduct.
\end{abstract}

ison of the native cytochrome $c$ digest to the modified sample, trypsinolysis of HNE-treated cytochrome $c$ resulted in ions at $\mathrm{m} / \mathrm{z} 1324.5$ and 1452.5 that represent putative $4 \mathrm{HNE}$ adducts. The former ion corresponds to the addition of a Michael adduct $(+156.1)$ to the peptide TGPNLHGLFGR $(\mathrm{m} / \mathrm{z} 1168.4)$ and the latter to a Michael adduct to the same peptide but with an additional lysine on the $C$ terminus. Trypsin typically cleaves at lysine and arginine amino acid residues. The enzymatic digestion of the 4HNE-modified protein could be retarded or even blocked by $4 \mathrm{HNE}$ - Schiff base or Michael additions to lysine residues on the protein, thus preventing the enzyme from recognizing possible cleavage sites. Nonetheless, trypsin digestion of 4HNE-modified cytochrome $c$ showed $75 \%$ sequence coverage upon MALDI-TOF analysis.

The use of chymotrypsin to digest the native and aldehyde-modified protein enhanced the possibility of detecting aldehyde-adducted peptides because the enzyme does not cleave at lysine residues. Chymotrypsin cleaves at aromatic residues including phenylalanine, tyrosine, and tryptophan. By comparison with the control sample shown in Figure 7a, putative Michael ad- ducts found in the modified protein sample include those with $\mathrm{m} / \mathrm{z}$ values 1174.7, 1438.9, and 1891.9 and putative Schiff base adducts include $\mathrm{m} / \mathrm{z}$ values 1300.8 and 1873.2. 4HNE-modified cytochrome $c$ digested with chymotrypsin showed $58 \%$ sequence coverage. Observed 4HNE-modified cytochrome $c$ peptide sequences with molecular weights above $900 \mathrm{Da}$ are outlined in Table 1.

Tandem mass spectrometry of the 4HNE-modified peptides gave conclusive data concerning specific amino acids to which 4 HNE had adducted (Figures $8-11$ ). Ion $\mathrm{m} / \mathrm{z} 139$ is seen in the spectrum of $4 \mathrm{HNE}-$ modified peptides shown in Figures 8-11. Bolgar and Gaskell reported a fragment common to $4 \mathrm{HNE}$-adducted histidine and cysteine amino acids was a dehydrated, protonated $4 \mathrm{HNE}$ at $\mathrm{m} / \mathrm{z} 139$ [23]. As such, selected ion extraction of $\mathrm{m} / \mathrm{z} 139$ was used to identify 4HNE-modified peptides.

Figure $8 \mathrm{a}$ and $\mathrm{b}$ show the liquid chromatographymass spectrometry (LC-MS)/MS spectra for the tryptic peptide TGPNLHGLFGR (residue numbers 28-38) for both native (Figure 8a) and 4HNE-modified protein (Figure $8 \mathrm{~b}$ ). A conclusive $\mathrm{b}$ and $\mathrm{y}$ ion fragmentation 


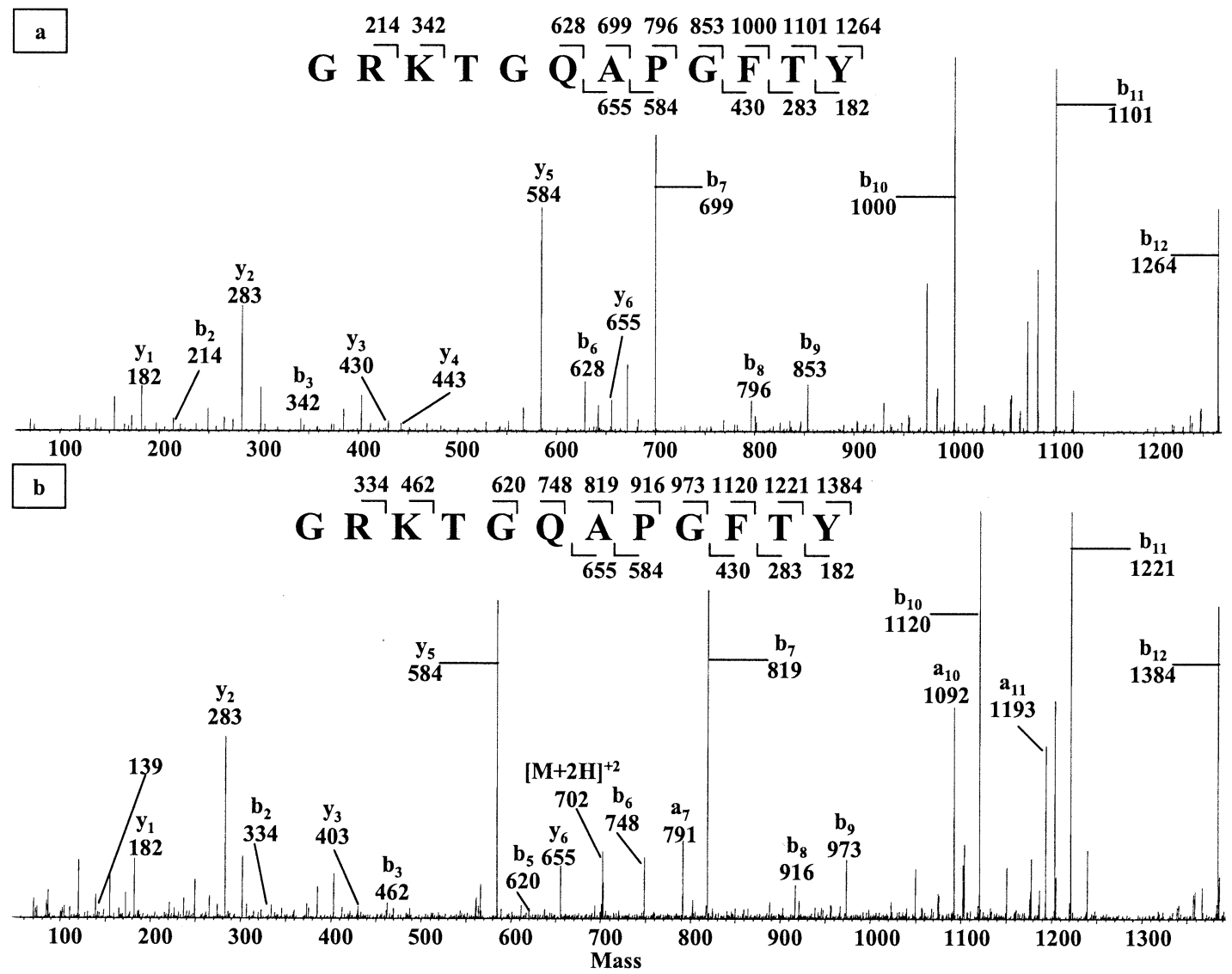

Figure 10. LC/MS/MS CID mass spectra of cytochrome $c$ using the QTOF. Cytochrome $c(2 \mathrm{mg} / \mathrm{mL})$ was incubated with $4 \mathrm{mM} 4 \mathrm{HNE}$ to create the aldehyde-modified protein. (a) Chymotryptically digested peptide GRKTGQAPGFTY of native cytochrome $c$. $[\mathrm{M}+2 \mathrm{H}]^{+2} 641$ is shown; $(\mathbf{b})$ chymotryptically digested peptide GRKTGQAPGFTY of native cytochrome $c$. $[\mathrm{M}+2 \mathrm{H}]^{+2} 701$ is shown. Upon comparison of $\mathrm{b}$ and $\mathrm{y}$ ion fragmentation patterns, Arg38 is modified by a $4 \mathrm{HNE}$ moiety forming a 2-pentylpyrrole adduct.

pattern exists for a Michael adduct on His33 of this peptide. Compared with the control peptide, most notable is the 156 increase in the both $\mathrm{b}_{6}$ and $\mathrm{y}_{6}$ ions in

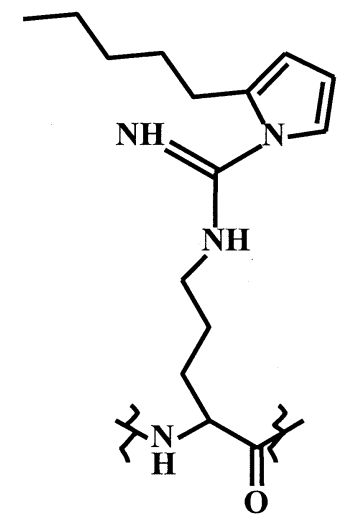

\section{HNE-Modified Arginine 2-Pentylpyrrole Adduct}

Figure 11. Proposed chemical structure of a $4 \mathrm{HNE}$-arginine pyrrole adduct. the 4HNE-modified peptide. Daughter b and y ions upstream from the addition site show consistent 156 increases in mass (including $\mathrm{y}_{7}, \mathrm{y}_{9}$, and $\mathrm{b}_{11}$ ). Based upon the characteristic 156 increase in relevant fragmentation ions, it was concluded the $4 \mathrm{HNE}$ reacted with the imidazole group of $\mathrm{H} 33$ to form a Michael adduct. The ion at $\mathrm{m} / \mathrm{z} 1168$ represents a neutral loss of the $4 \mathrm{HNE}$ molecule from the $4 \mathrm{HNE}$-adducted peptide.

LC-MS/MS spectra of the native and 4HNE-modified forms, respectively, of the chymotryptic peptide AGIKKKTEREDLIAY (residue numbers 83-97) in Figure $9 \mathrm{a}$ and $\mathrm{b}$. A conclusive $\mathrm{b}$ and $\mathrm{y}$ ion fragmentation pattern exists for a $4 \mathrm{HNE}$-pyrrole adduct on Lys 87 of this peptide. Increases of $\mathrm{m} / \mathrm{z} 120$ beginning at the $\mathrm{b}_{5}$ and $\mathrm{y}_{11}$ ions are seen in the aldehyde-modified peptide when compared with the control. Ions upstream of the adduction site show 120 mass unit increases as well, including ions $b_{11}-b_{15}, y_{12}$, and $y_{15}$. Based upon the $b$ and $y$ ion increase of 120 of the specific modified amino acid and upstream partners, it was concluded that $4 \mathrm{HNE}$ adducted the free amino group of K87 forming a 2-pentylpyrrole adduct.

LC-MS/MS spectra of the chymotryptic peptide 
Table 2. Native and 4HNE-modified cytochrome $c$ peptides observed by LC-MS/MS after enzymatic digestion

\begin{tabular}{lcccccc}
\hline & Unmodified & $\begin{array}{c}\text { Unmodified } \\
\text { peptide } \\
\text { calculated } \\
{[\mathrm{M}+2 \mathrm{H}]^{+}}\end{array}$ & $\begin{array}{c}\text { 4HNE-modified } \\
\text { peptide observed } \\
{[\mathrm{M}+2 \mathrm{H}]^{+}}\end{array}$ & $\begin{array}{c}\text { 4HNE-modifed } \\
\text { peptide } \\
\text { calculated } \\
{[\mathrm{M}+2 \mathrm{M}+2 \mathrm{H}]^{+}}\end{array}$ & $\begin{array}{c}\text { Amino acid } \\
\text { modified }\end{array}$ \\
\hline \hline TGPNLHGLFGR & $28-38$ & 584.8 & 584.3 & 662.8 & 662.3 & $\mathrm{H} 33$ \\
GRKTGQAPGFTY & $37-48$ & 641.8 & 641.3 & 701.9 & 701.3 & $\mathrm{R}$ \\
AGIKKKTEREDLIAY & $83-97$ & 868.0 & 867.5 & 928.1 & 927.5 & $\mathrm{~K} 87$ \\
\hline
\end{tabular}

GRKTGQAPGFTY (residue numbers 37-48) are shown in both its native (Figure 10a) and 4HNE-modified forms (Figure 10b). Interestingly, upon a close examination, a conclusive $b$ ion fragmentation pattern exists for a 4HNE-pyrrole adduct on Arg38 of this peptide. Most notable is the increase in mass of the aldehydeadducted amino acid's $b_{2}$ ion when compared to control from $b_{2}=214$ to $b_{2}=334$. Daughter $b$ ions, all with a 120 increase in mass upstream from the adduction site, exist including $b_{3}$ and $b_{5}-b_{12}$. $Y$ ions upstream from the adduction site, namely the $\mathrm{y}_{12}$ ion, were not detected.

Although Doorn and Petersen demonstrated the formation of aldehyde-arginine adducts using 4-oxononenal, a lipid peroxidation byproduct similar in structure to $4 \mathrm{HNE}$, and model peptides, $4 \mathrm{HNE}$-arginine adducts of protein amino acids have not been previously detected [34]. Due to the nucleophilic nature of the free amino group in the arginine side chain, the formation of $4 \mathrm{HNE}$-arginine adducts is a plausible event. Theoretical arginine-aldehyde modifications include the Michael, Schiff base, and 2-pentylpyrrole adducts. Our results of LC-MS/MS experiments shown in Figure 10 indicate the formation of an arginine-pyrrole adduct of cytochrome $c$. Figure 11 shows the proposed chemical structure of an arginine-pyrrole adduct. Table 2 outlines the LC-MS/MS data for the 4HNE-modified peptides for which conclusive $b$ and $y$ ion fragmentation patterns exist, localizing the specific amino acid to which the aldehyde adducted.

Other peptides containing both 138 and $156 \mathrm{Da}$ additions were detected, but their fragmentation patterns were not conclusive for site of modification, most probably because a reduction step was not performed to stabilize labile adducts. Based on the molecular masses of the peptides, additional $4 \mathrm{HNE}$-adduction to the peptides Ac-GDVEKGKKIF (residue numbers 1-10), GRKTGQAPGFTY (residue numbers 37-48), and AGIKKKTEREDLIAY (residue numbers 83-97) was apparent (data not shown). The fragmentation patterns were similar to the corresponding unmodified peptides, but not definitive for localizing site(s) of modification.

An X-ray crystal structure of horse heart cytochrome $c$ with the heme group bound was used to evaluate the sites of modification by $4 \mathrm{HNE}$ (Figure 12). The side chains of amino acids established by LC-MS/MS experiments to be modified by $4 \mathrm{HNE}$ are labeled using a space-filling model. It is significant that Lys87 is in- volved in the binding of cytochrome $c$ to both cytochrome $c$ reductase and cytochrome $c$ oxidase [32].

\section{Conclusions}

Results from mass spectrometry experiments discussed within describe the interaction of $4 \mathrm{HNE}$, a secondary product of lipid peroxidation, and nucleophilic amino acid residues of cytochrome $c$, a mitochondrial protein essential to electron transport, by covalent modification forming protein-aldehyde adducts. Our data demonstrate that $4 \mathrm{HNE}$ can form as many as four adducts with cytochrome $c$. The amino acids H33, K87, and R38 are modified by this aldehyde under in vitro conditions, and a decrease in protein $\mathrm{pI}$ occurs as a result of this modification. Of particular interest is the modification of arginine which has not been reported previously.

Our work demonstrates the utility of MALDI-TOF to investigate protein modification by this aldehyde as current literature suggests ESI conditions may produce artifactual adducts. Results from intact protein studies using MALDI-TOF to determine stoichiometry of adduct formation demonstrated that as many as four 4 HNE molecules can form covalent bonds with amino acid side chains of cytochrome $c$. The use of mass spectrometry to study the intact protein forms was enhanced by digesting the native and $4 \mathrm{HNE}$-modified samples with different enzymes and subjecting the

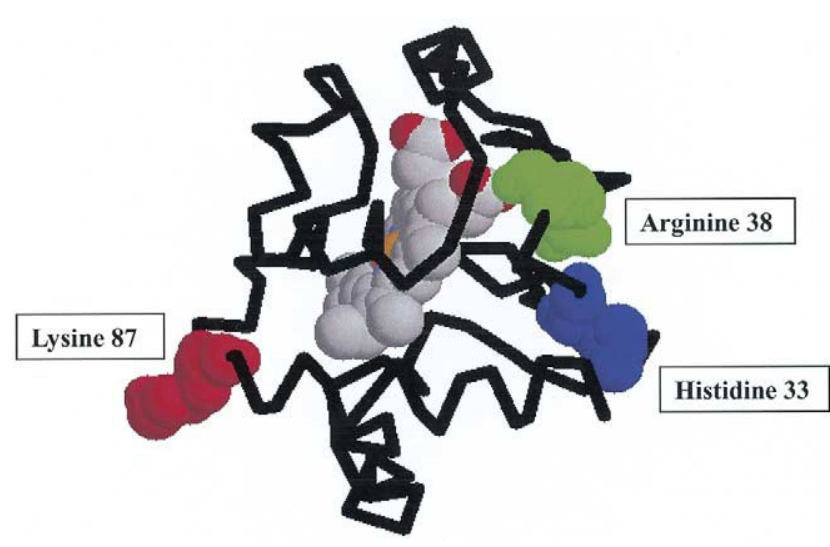

Figure 12. Diagram of horse heart cytochrome $c$ containing the bound heme group. The backbone of the protein is shown in black. Amino acids found by tandem MS experiments to be modified by $4 \mathrm{HNE}$ are colored, labeled, and side-chains are represented using the space-filling model. 
resulting peptides to sequencing techniques to locate sites of adduction. Peptide mass fingerprinting of both native and $4 \mathrm{HNE}$-modified protein using trypsin and chymotrypsin suggested several additions of aldehyde to cytochrome $c$ peptides in both Schiff base and Michael addition forms.

Data from isoelectric focusing experiments presented within suggest 4 HNE-modification of charged amino acid residues including lysines and arginines in cytochrome $c$ resulting in a decreased protein pI. Our results from this experiment indicate that one or more charged amino acids are modified by $4 \mathrm{HNE}$ under in vitro conditions. LC-MS/MS experiments indicated that, under conditions described within, 4HNE can interact with $\mathrm{H} 33$ forming a Michael adduct, and K87 and R38 forming 2-pentylpyrrole adducts. In completing its task of shuttling electrons between Complexes III and IV in the electron transport chain, cytochrome $c$ alternatively binds the complexes through an interaction with specific lysine molecules. $4 \mathrm{HNE}$ adduction of lysine residues such as K87 during lipid peroxidation could potentially have significant effects on enzyme binding capabilities, as well as electron transport efficiency. Our work described here demonstrates the value of a combined proteomic and mass spectrometry approach to study issues of post-translational modification of protein due to cellular events such as lipid peroxidation.

\section{Acknowledgments}

These studies were supported in part by a grant P50 AT00477-03 to SB and RO1-ES10167 to VDU from the National Center for Complementary and Alternative Medicine and the Office of Dietary Supplements at the National Institutes of Health to the Purdue University-University of Alabama at Birmingham Botanicals Center for Age-related Research and the National Institute of Environmental Sciences. The mass spectrometers used to generate the data were purchased using funds provided by Shared Instrumentation Grants (S10 RR11329 and S10 RR13795) from the National Center for Research Resources and an award from the UAB Health Services Foundation General Endowment Fund to SB. The UAB Comprehensive Cancer Center Mass Spectrometry Shared Facility is supported by a core grant (P30 CA-13148) from the National Cancer Institute. ALI was supported by a graduate fellowship from the NSF GK-12 program.

\section{References}

1. Villani, G.; Attardi, G. In Vivo Control of Respiration by Cytochrome C Oxidase in Human Cells. Free Rad. Biol. Med. 2000, 29, 202-210.

2. ProteinProspector. http://prospector.ucsf.edu/ (accessed 6/30/03).

3. Paradies, G.; Petrosillo, G.; Pistolese, M.; Ruggiero, F. M. Reactive Oxygen Species Affect Mitochondrial Electron Transport Complex I Activity through Oxidative Cardiolipin Damage. Gene 2002, 286, 135-141.

4. Petrosillo, G.; Ruggiero, F. M.; Pistolese, M.; Paradies, G. Reactive Oxygen Species Generated from the Mitochondrial Electron Transport Chain Induce Cytochrome $C$ Dissociation from Beef Heart Submitochondrial Paricles via Cardiolipin Peroxidation. Possible Role in Apoptosis. FEBS Lett. 2001, 509, 435-438.
5. Cassina, A. M.; Hodara, R.; Souza, J. M.; Thomson, L.; Castro, L.; Ischiropoulos, H.; Freeman, B. A.; Radi, R. Cytochrome C Nitration by Peroxynitrite. J. Biol. Chem. 2000, 275, 2140921415.

6. Capaldi, R. A.; Darley-Usmar, V. M.; Fuller, S.; Millett, F. Structural and Functional Features of the Interaction of Cytochrome $C$ with Complex III and Cytochrome $C$ Oxidase. FEBS Lett 1982, 138, 1-7.

7. Millett, F.; Darley-Usmar, V. M.; Capaldi, R. A. Cytochrome C is Crosslinked to Subunit II of Cytochrome C Oxidase by a Water Soluble Carbodiimide. Biochemistry 1982, 21, 3857-3862.

8. Capaldi, R. A.; Malatesta, F.; Darley-Usmar, V. M. Structure of Cytochrome C Oxidase. Biochim. Biophys. Acta 1983, 726, 135-148.

9. Ramachandran, A.; Levonen, A. L.; Brookes, P. S.; Ceaser, E.; Shiva, S.; Barone, M. C.; Darley-Usmar, V. Mitochondria, Nitric Oxide, and Cardiovascular Dysfunction. Free Rad. Biol. Med. 2002, 33, 1465-1474.

10. Schonhoff, C. M.; Gaston, B.; Mannick, J. B. Nitrosylation of Cytochrome C During Apoptosis. J. Biol. Chem. 2003, 278, 18265-18270.

11. Uchida, K. Role of Reactive Aldehyde in Cardiovascular Disease. Free Rad. Biol. Med. 2000, 28, 1685-1696.

12. Hashimoto, M.; Sibata, T.; Wasada, H.; Toyokuni, S.; Uchida, K. Structural Basis of Protein-Bound Endogenous Aldehydes. J. Biol. Chem. 2003, 278, 5044-5051.

13. Esterbauer, H.; Schaur, R. J.; Zollner, H. Chemistry and Biochemistry of 4-Hydroxynonenal, Malonaldehyde, and Related Aldehydes. Free Rad. Biol. Med. 1991, 11, 81-128.

14. Picklo, M. J.; Amarnath, V.; McIntyre, J. O.; Graham, D. G.; Montine, T. J. 4-Hydroxy-2(E)-Nonenal Inhibits CNS Mitochondrial Respiration at Multiple Sites. J. Neurochem. 1999, 72, 1617-1624.

15. Humphries, K. M.; Yoo, Y.; Szweda, L. I. Inhibition of NADHLinked Mitochondrial Respiration by 4-Hydroxy-2-Nonenal. Biochemistry 1998, 37, 552-557.

16. Vieira, H. L. A.; Belzacq, A.; Haouzi, D.; Bernassola, F.; Cohen, I.; Jacotot, E.; Ferri, K. F.; Chahrazed, E. H.; Bartle, L. M.; Melino, G.; Brenner, C.; Goldmacher, V.; Kroemer, G. The Adenine Nucleotide Translocator: A Target of Nitric Oxide, Peroxynitrite, and 4-Hydroxynonenal. Oncogene 2001, 20, 4305-4316.

17. Uchida, K.; Toyokuni, S.; Nishikawa, K.; Kawakishi, S.; Oda, H.; Hiai, H.; Stadtman, E. R. Michael Addition-Type 4-Hydroxy-2-Nonenal Adducts in Modified Low-Density Lipoproteins: Markers for Atherosclerosis. Biochemistry 1994, 41, 12487-12494.

18. Kastenbauer, S.; Koedel, U.; Becker, B. F.; Pfister, H. W. Oxidative Stress in Bacterial Meningitis in Humans. Neurology 2002, 58, 186-191.

19. Yamashita, T.; Ando, Y.; Obayashi, K.; Terazaki, H.; Sakashita, N.; Uchida, K.; Ohama, E.; Ando, M.; Uchino, M. Oxidative Injury is Present in Purkinje Cells in Patients with Olivopontocerebellar Atrophy. J. Neurol. Sci. 2002, 175, 107-110.

20. Rahman, I.; van Schadewijk, A. A. M.; Crowther, A. J. L.; Hiemstra, P. S.; Stolk, J.; MacNee, W.; De Boer, W. I. 4-Hydroxy-2-Nonenal, a Specific Lipid Peroxidation Product, is Elevated in Lungs of Patients with Chronic Obstructive Pulmonary Disease. Am. J. Resp. Crit. Care Med. 2002, 166, 490495.

21. Bennaars-Eiden, A.; Higgins, L. A.; Hertzel, A. V.; Kapphahn, R. J.; Ferrington, D. A.; Bernlohr, D. A. Covalent Modification of Epithelial Fatty Acid-Binding Protein by 4-Hydroxynonenal in Vitro and in Vivo. J. Biol. Chem. 2002, 277, 50693-50702.

22. Fenaille, F.; Guy, P. Study of Protein Modification by 4-Hydroxy-2-Nonenal and Other Short Chain Aldehydes Analyzed 
by Electrospray Ionization Tandem Mass Spectrometry. J. Am. Soc. Mass Spectrom. 2003, 14, 215-226.

23. Bolgar, M. S.; Gaskell, S. Determination of the Sites of 4-Hydroxy-2-nonenal Adduction to Protein by Electrospray Tandem Mass Spectrometry. Anal. Chem. 1996, 68, 2325-2330.

24. Sayre, L. M.; Zelasko, D. A.; Harris, P. L. R.; Perry, G.; Salomon, R. G.; Smith, M. A. 4-Hydroxynonenal-Derived Advanced Lipid Peroxidation End Products are Increased in Alzheimer's Disease. J. Neurochem. 1997, 68, 2092-2097.

25. Mattson, M. P.; Perdersen, W. A.; Duan, W.; Culmsee, C.; Camandola, S. Cellular and Molecular Mechanisms Underlying Perturbed Energy Metabolism and Neuronal Degeneration in Alzheimer's and Parkinson's Diseases. Ann. N.Y. Acad. Sci. 1999, 893, 154-175.

26. Choi, S.; Ju, W.; Choi, E.; Kim, J.; Lea, H.; Carp, R. I.; Wisniewski, H. M.; Kim, Y. Mitochondrial Dysfunction Induced by Oxidative Stress in the Brains Of Hamsters Infected with the 263 K Scrapie Agent. Acta Neuropathol. 1998, 96, 279-286.

27. Li, C. J.; Nanji, A. A.; Siakotos, A. N.; Lin, R. C. AcetaldehydeModified and 4-Hydroxynonenal-Modified Proteins in the Livers of Rats with Alcoholic Liver Disease. Hepatology 1997, $26,650-657$.
28. Jaeschke, H.; Gores, G. J.; Cederbaum, A. I.; Hinson, J. A.; Pessayre, D.; Lemasters, J. J. Mechanisms of Hepatotoxicity. Toxicol. Sci. 2002, 65, 166-176.

29. Chen, J. J.; Schenker, S.; Henderson, G. I. 4-Hydroxynonenal Levels are Enhanced in Fetal Liver Mitochondria by in Utero Ethanol Exposure. Hepatology 1997, 25, 142-147.

30. Pepe, S. Mitochondrial Function in Ischemia and Reperfusion of the Aging Heart. Clin. Exp. Pharmacol. Physiol. 2000, 27, 745-750.

31. Chen, Q., Vazquez, E. J., Moghaddas, S., Hoppel, C. L., Lesnefsky, E. J. Production of Reactive Oxygen Species by Mitochondria: Central Role of Complex III. J. Biol. Chem. 2003, July 2 [Epub ahead of print].

32. Reider, R.; Bosshard, H. R. Comparison of the Binding Sites on Cytochrome $C$ for Cytochrome $C$ Oxidase, Cytochrome $B C_{1}$, and Cytochrome $C_{1}$. J. Biol. Chem. 1980, 255(10), 4732-4739.

33. Liu, Z.; Minkler, P. E.; Sayre, L. M. Mass Spectroscopic Characterization of Protein Modification by 4-Hydroxy-2-(E)Nonenal and 4-Oxo-2-(E)-Nonenal. Chem. Res. Toxicol. 2003, 16, 901-911.

34. Doorn, J. A.; Petersen, D. R. Covalent Modification of Amino Acid Nucleophiles by the Lipid Peroxidation Products 4-Hydroxy-2-Nonenal and 4-Oxo-2-Nonenal. Chem. Res. Toxicol. 2002, 15, 1445-1450. 